Abstracta Iranica Abstracta Iranica

Revue bibliographique pour le domaine irano-aryen

Volume 31 | 2011

Comptes rendus des publications de 2008

\title{
«L'histoire sous forme graphique en arabe, persan et turc ottoman. Origines et fonctions ». Bulletin d'études orientales, vol. 58, 2008, p. 1-41.
} Jacqueline Sublet

\section{OpenEdition}

1 Journals

Édition électronique

URL : http://journals.openedition.org/abstractairanica/39281

DOI : 10.4000/abstractairanica.39281

ISSN : 1961-960X

Éditeur :

CNRS (UMR 7528 Mondes iraniens et indiens), Éditions de l'IFRI

Édition imprimée

Date de publication : 15 mai 2011

ISSN : 0240-8910

Référence électronique

Jacqueline Sublet, « «L'histoire sous forme graphique en arabe, persan et turc ottoman. Origines et fonctions ». Bulletin d'études orientales, vol. 58, 2008, p. 1-41. », Abstracta Iranica [En ligne], Volume 31 । 2011, document 121, mis en ligne le 11 octobre 2012, consulté le 05 octobre 2020. URL : http:// journals.openedition.org/abstractairanica/39281 ; DOI : https://doi.org/10.4000/abstractairanica. 39281

Ce document a été généré automatiquement le 5 octobre 2020.

Tous droits réservés 


\section{«L'histoire sous forme graphique en arabe, persan et turc ottoman. Origines et fonctions ». Bulletin d'études orientales, vol. 58, 2008,} p. 1-41.

Jacqueline Sublet

$1 \quad$ Le titre du bel article de D. Aigle est énigmatique : le lecteur découvre au fil des pages qu'il s'agit de l'exposé de faits historiques au moyen de tableaux, dont la valeur esthétique n'est d'ailleurs pas la moindre des qualités. Il est heureux de trouver une étude qui prenne en compte la présentation des textes dans les sources manuscrites et de souligner que leur cadre dépasse le domaine des textes d'ordre scientifique tels que les manuels d'astronomie, les textes médicaux, les ouvrages de géographie ou de rares répertoires biographiques. L'A. définit avec acuité les termes génériques qui servent à caractériser cette forme de représentation figurée appelée taqvìm ou jadval et les considère en fonction de leur contexte, comme en témoignent les notes documentées et la riche bibliographie. Elle attire l'attention du lecteur sur les textes historiques qui se sont développés dans les mondes persan et turc dès le XIV ${ }^{e}$ s., et dont les auteurs ont, avec l'appui des calligraphes, plié le texte narratif à cette exigence graphique nouvelle pour présenter, de manière à la fois didactique et particulièrement harmonieuse, une narration historique à la fois riche en événements et lourde de tradition littéraire.

2 Les onze documents présentés en annexe proviennent de bibliothèques de divers pays, et illustrent somptueusement le propos de l'auteur. Les traductions des données biographiques proposées en regard de l'un des documents révèlent la richesse des informations à glaner dans ce genre de documents en traçant le portrait sans complaisance et le destin tragique, parfois crûment présenté, de trois souverains de la lignée du Chupanide Malik Ašraf Kučik. 
3 Le contenu de l'article ouvre des pistes de recherche nouvelles et ne peut qu'encourager les chercheurs à publier dans un premier temps ces documents exceptionnels en tenant compte de leur originalité esthétique. L'histoire sous forme graphique telle qu'elle est découverte ici donne à espérer qu'une collecte systématique de manuscrits soit entreprise à l'échelle internationale et puisse initier recherches et publications.

INDEX

Thèmes : 4.1. Histoire médiévale

\section{AUTEURS}

JACQUELINE SUBLET

I.R.H.T. - C.N.R.S - Paris 